\title{
Study on the Network Externality of the Sharing Bikes
}

\author{
$\mathrm{Li} \mathrm{Wu}$ \\ East China University of Political Science and Law, China 200042 \\ shealingham@163.com
}

Keywords: Sharing bikes; Network externality; Endogenous variable; New economy

\begin{abstract}
In China, The sharing bikes have become the trend of the short-distance travel tools, especially in megacities. However, the study of shared bicycle literature is very scarce. This paper is going to use network externality theory and methods, so as to reveal the network externality of the new things. Though in many papers the network externality is a exogenous variable, we argued that network externality is the endogenous variables in the process of the sharing bikes. Finally, we made the conclusion that the network externality is not exogenous. It can be an endogenous and the network externality is quite important for the sharing bikes industry.
\end{abstract}

\section{Introduction and Summary}

Mobei bicycle, developed by a Chinese start-up companies are rapidly sweeping the country. Using the mobike App, users can use their mobile phone to view the bicycle location, and then make an appointment and find the bike. By scanning the two-dimensional code, users can unlock the car and start riding. When they arrive at the destination, users manually lock the bike in the street which arbitrarily painted white line to complete the return formalities. Mobike is just one of the most brands of shared bicycle brands. In fact, sharing bikes is in the early stages of competition, industry scale is not big enough. Although the prospects for sharing bicycles are difficult to predict, some characteristics of the industry are still very obvious, such as network externalities.

Roland Berger has released "2018 China car sharing travel market analysis and forecast report". In this report, Roland Berger pointed out that China has formed a \$ 62.5 billion shared economy market, and maintained rapid growth of 54\%.Roland Berger predicted that by 2018 the Chinese share market is expected to reach 230 billion US dollars, accounted by the $33 \%$ to $44 \%$ in the global economy, and Cnina will become the leading market around world. The report points out that car sharing travel in China has broad prospects, its direct demand reach to 816 million times / day in 2015, rapid growth in 2018 to 37 million times / day, the corresponding market capacity is expected to grow from 66 billion yuan / year to 380 billion yuan / year, while the potential demand for potential market capacity is expected to reach 1.8 trillion yuan. Car sharing travel will become unlimited blue ocean ${ }^{[1]}$.Sharing bikes' market size growth is similar to the car sharing market.

\section{The Origin of the Network Externalities}

It is generally believed that the first analysis of network externalities is an economist Roll Graves ( $\mathrm{J}$. Rohlfs). However, according to Roll Cliffs, the economists Atr and Affleck Las (R. Artle and C. Averours) are the first to propose the communication service to the individual's incremental utility as a function of the number of users, and a dynamic model to demonstrate the interdependence of the communication needs to maintain communication services continued to increase. However, from the studies of systemic, Roll Hargreaves is still the devaluation.

In the study of the telephone network, Roll Graves found that a user's utility from the communication service increases by the number of joining in the system, and this is a typical example of external economic consumption, an important role to the communications industry basic economic analysis. Consumer preferences given, the cumulative service demand function by Consumer external economic generating the communication service inverted U-shaped demand curve. The presence of U-shaped demand curve, made the communication services market balanced at any given price, mostly depending on a balanced process of adjustment. The U-shaped demand 
curve produced the start-up problem of the market size. Rohr Hargreaves believes that solutions to start-up problems depend largely on the demand model, the user preferences in the same case, and the start-up problem is just a start over "critical capacity" (critical mass).[2]

By a simple demand and supply model, we can show up this inverted U-shaped curve, the model of network externalities. We assume sharing bike is a product with network externalities. And we assume that the bike to the $\mathrm{v}$ of consumers, $\mathrm{vn}$ as its value, where $\mathrm{n}$ is the number of all consumption of the bike. The more the number of goods is consumed, the higher the price every consumer is willing to pay for the goods, because it means more possibility to obtain the bike. In the model, the demand curve is no longer the standard downward-sloping shape.

If the price is $p$, there will be no difference between buying it or not for a consumer in the market. So that $\mathrm{v}$ ' stands for the marginal consumers. According to the concept of margin, there should be no difference between buying the goods or not for a consumer. Therefore, the consumers' willingness to pay for this product is equivalent to the price at this time:

$\mathrm{P}=\mathrm{v}$ 'n

Since the marginal consumer is no difference, compared with $v$ ', each consumer with a higher $\mathrm{v}$ value will buy goods. At this point, the number of consumers wants to buy commodities as follows:

$\mathrm{n}=1000-\mathrm{v}$

Vertical joint (1) and (2), the market equilibrium conditions are:

$\mathrm{P}=\mathrm{n}(1000-\mathrm{n})$

This equation gives the relationship between the number of consumers and commodity prices. From this relationship, it can be a demand curve; If there are n consumers to buy goods, it is obvious that the height of the demand curve represents the marginal consumer's willingness to pay [3].

The demand curve is inverted $U$ type. Study this demand curve. It is completely different from the standard downward-sloping demand curve standards. If the number of consumers associated with the network is small, the marginal consumer's willingness to pay will be lower, due to consumer contact and the small number of other consumers. If there are a lot of consumers in the network, other consumers with a higher evaluation of the goods has been involved, so the rest of the marginal consumer's willingness to pay is still low. These two forces ultimately led to an inverted U type of demand curve.

\section{Network Externality Endogenous Mechanism Research of the Sharing Bikes}

Model Description. This model is going to separate the whole sharing bikes into 2 parts. These 2 parts present a complements pattern, which is good to analysis the substance of the problem. The economic significance and reality are just as followings ${ }^{[4]}$ :

1. The sharing bikes itself is a big network; its main point is to connect and communicate people. Therefore, the single bike cannot construct the net to service the public.

2. The purpose of consumers buying the single product is to get the function, which can represent the position of the sharing bikes' relative industrial chain. And without this chain, the effect of the single product will not be the effect which consumers' hope.

3. Though consumers spend the single price on buying the relative products probably, but actually, every single product has associated products or service supporting, which will present in an integrated way.

Based on the above reasons, this model is going to suppose the whole sharing bikes to 2 complements parts to each other. [5]

Suppose the whole market has $\mathrm{N}$ consumers, $\mathrm{T}$ distinguishing equipment suppliers whose technology is not fit to each other. Among them, there's $n_{t}$ consumers decide to take the No.t equipment supplier's equipment, and we take the price as $P_{t}, \mathrm{t}=1,2 \ldots \mathrm{T}$, while this time, the whole network has $n_{t}-1$ relation probabilities in all. And let's suppose the No. i consumer and No. k 
consumer's portfolio is $z_{i k}, i \neq k$. Thus, consumer $\mathrm{I}$ in the $\mathrm{t}$ system's total portfolio will be $z_{i}=\sum_{i=1}^{t_{k}-1} z_{i k}=z_{k}=\sum_{k \neq i} z_{i k}$.

Let's make the consumer utility function as: $u_{i t}=\theta_{i t}+E\left[Z_{i t}+z_{i 0}\right], \theta_{i t}$ as the single utility of buying the equipment, which is decided by the consumer's preference. $Z_{i t}=\left[\sum_{k=1}^{n_{1}-1} z_{i k}^{\frac{1}{\beta}}\right]^{\beta}$ for the CES utility function. When $\beta>1, Z_{i t}$ is the decreasing convex function of the marginal utility, so we suppose $\beta>1$. $z_{i 0}$ present the other products which consumers can consume, and the unit of value is 1 .

If we suppose consumer I 's income is $y_{i}$, equipment t's price as $P_{t}$, and $\rho_{\mathrm{t}}$ present the expense which equipment has to paid to the network service provider. Consumers will take 2 steps to make the consumption choice: first step, consumers will make the choice between the cost of external products and the cost of distinguishing the equipment. The second step, consumers have to decide how to use this distinguishing equipment.

And for more technical reasons, we will make the explanation with principle of the sharing bikes. The sharing bikes load the information and take off the money from banking accounts in the smartphone which are advanced binding automatically though RFID (radio frequency identification) on the bikes. This is not only a specific practice in the sharing bikes, but also an electronic system which are connected into a network.

\section{Conclusions and Suggestions}

Combination of network externalities and the sharing bikes related literature, we can find, there are many literatures about the network externalities, but there are still some shortages of the study. At the same time, aiming at the network externalities of the sharing bikes industry research is almost blank, there are few mentioned this field in the articles. Above all the specific performance:

A. The domestic and foreign study about the network externality theory and empirical analysis is based on the assumption that mostly in advance with the network externalities exogenous, and around the compatibility and technical options to launch, lack of study with the mechanism of network externalities.

B. Although some literatures had a lot of theoretical research, and had the definition of the sharing bikes, but there is still no system research in the industry of the sharing bikes.

C. At present, there is rarely literature whatever domestic and foreign study about the relationship with the network externalities and the development of the sharing bikes. It is necessary to make a further research in theory and in practice of the sharing bikes industry and use the theory to provide much more detailed guidance for the development of the industry.

\section{References}

[1] Information on http://tech.huanqiu.com/news/2016-10/9582182.html

[2] Choi, Byung-Rok, High-technology Development in Regional Economic Growth: Policy Implications of Dynamic Externalities Burlington. (USA): Ashgate Publishing Company. 2003.

[3] Hal R.Varian, Intermediate Microeconomics: A Modern Approach, Sixth Edition. W.W.Norton \& Company, Inc.2003.

[4] Michael L. Katz, Carl Shapiro, Network externalities, competition, and compatibility. The America Economic Review, Vol.75, No.3.1985.

[5] M. Blouski, Network externalities and two-part tariffs in telecommunicaton Markets. 
Information Economics and Policy, Vol 14, 95 109.2002.

[6] Demaio P. Bike-sharing: History, Impacts, Models of Provision, and Future. Journal of Public Transportation, 2009, 12(4).

[7] Shaheen S A, Guzman S, Zhang H. Bikesharing in Europe, the Americas, and Asia: Past, Present, and Future. Transportation Research Record Journal of the Transportation Research Board, 2010, 2143(1316350):159-167.

[8] Raviv T, Tzur M, Forma I A. Static repositioning in a bike-sharing system: models and solution approaches. Euro Journal on Transportation \& Logistics, 2013, 2(3):187-229.

[9] Chemla D, Meunier F, Calvo R W. Bike sharing systems: Solving the static rebalancing problem. Discrete Optimization, 2013, 10(2):120-146.

[10] Shaheen S A, Cohen A P, Martin E W. Public Bikesharing in North America: Early Operator Understanding and Emerging Trends. Transportation Research Record Journal of the Transportation Research Board, 2013, 1568(2387):83-92. 